\title{
Measuring the Capabilities of the Swedish Fire Service to Save Lives in Residential
} Fires

\author{
Marcus Runefors* (D, Division of Fire Safety Engineering, Lund University, \\ Lund, Sweden
}

Received: 2 January 2019/Accepted: 15 July 2019

\begin{abstract}
The ability of the fire service to save lives in building fires has a profound impact on planning. However, very little empirical data are available on how different factors affect this capability - or even how many that are rescued annually. The current paper aims to partly fill this gap with an assessment of all rescues performed by the fire departments in Sweden during 2017. A combination of incident reports and a large number of post-event interviews yielded a total of 51 rescues (to be compared to 88 fatalities) during that year, which show that the fire service has a great potential to reduce the number of fire fatalities. In these cases, the call to the dispatcher most frequently came from a neighbor $(55 \%)$ or the victim $(26 \%)$. The rescue was in $71 \%$ of the cases performed with interior attack with a breathing apparatus. The cases were also compared with fatal fires revealing that the odds of successful rescue increased, for example, if the fire occurred in an apartment building or if the response time was short. The joint data set of rescues and fatal fires was used to develop a methodology to calculate the probability of successful rescue depending on the capability of the fire service. This methodology provides the first fully empirical method for organizing the fire service in relation to saving lives in fires. A similar approach should be pursued for other accident types and consolidated for an evidence based assessment of the capability of the fire service.
\end{abstract}

Keywords: Fire service, Rescue, Capability, Fatal fire, Residential fire

\section{Introduction}

Performing rescue operations in building fires is often perceived as being a core activity of fire departments, and often has a fundamental impact on staffing and location of fire stations. However, very little empirical research has been conducted into the nature of actual rescue operations to determine the factors that influence the potential success of such interventions. One previous study has been identified that originates in the Netherlands and compares fatal fires with cases of rescued individuals, based on a number of variables [1]; but, the definition of rescue is wider than the one used in the current paper since the previous study does

\footnotetext{
* Correspondence should be addressed to: Marcus Runefors, E-mail: marcus.runefors@brand.lth.se
} 
not require immediate threat to life and health. There is also a recent study on the influence of response time on the risk of dying in fires [2]. In this paper, the approaches in the two studies were combined to provide a description and measure of the capability of the rescue services ability to save lives during residential fires.

Location (and to a lesser degree staffing and resources) of the fire service has gained considerable attention from operational research from the sixties and onward and there are a vast numbers of optimization algorithms and mappings in the literature (see [3] for a review). These span from simple driving time optimization [4] to more complex models including, for example risk maps and different types of rescue units [5]. The models do give some guidance for planning; but, since they are generally not based on empirical data concerning the impact of the response on the outcome, they become too simplified to answer many questions that are important in practice. There are some examples of empirical work in relation to fire department intervention to limit fire spread in buildings [6-9], but they generally take no or very simplified account of lives saved by the fire service. They are therefore judged not to be useful to contrast the findings in the current paper.

Examples of questions relating to changes in capability that cannot be answered without a thorough empirical material include: Will the outcome, on average, be better with one fire fighter arriving in 5 min compared to five firefighters arriving in $10 \mathrm{~min}$ ? Will the outcome be significantly better if an additional fire fighter were added to the crew? The method is primarily intended to guide long term planning of location, staffing and choice of equipment for fire stations and not as guidance to the dispatcher, since the choice of units to dispatch is commonly more related to the size of the fire which is not necessarily correlated to the risk to individuals. In practice, the results of the model also need to be combined with other factors before an optimum can be found.

The questions above are very complicated in nature and difficult to address scientifically, but in order to organize the fire service in an effective way it is vital to give some evidence to guide the decision even if a final optimum response posture is unlikely ever to be found.

The current paper aims to provide guidance on the following questions:

1. How many lives, per year, are saved by firefighters in building fires in Sweden?

2. What are the differences and similarities between cases with fatalities and rescued?

3. How can the fire department's capability for saving lives during building fires be quantified?

\section{Methods and Data}

\subsection{Data}

For data on individuals rescued by the fire departments, a two-step process was employed. The first step entailed obtaining data from the incident statistics data- 
base maintained by the Swedish Civil Contingencies Agency (MSB) which includes information on the vast majority of incidents in Sweden involving response by fire departments. Typically, one to five small municipalities are lacking in the material. In 2013 two municipalities covering $0.2 \%$ of the population [10] were lacking giving a total coverage of approximately $99.8 \%$ of all incident responses. The database includes variables on whether any individuals have been rescued and how (i.e. manual ladder, aerial apparatus or interior rescue). The variables in the incident statistics alone are not enough to determine how many are rescued since many of the evacuated individuals are people not directly at risk of being harmed by the fire, and there are also errors in the data [11].

During 2017, the author continuously received incident reports from events where the fire department indicated in the incident report that they had performed a rescue - in total 146 cases. For these cases, if it was not obvious from the free text that it was not a rescue or if the individual was known to have died, the fire commander first at scene was contacted either through e-mail or via telephone to verify whether the cases contains actual rescues or not (see Fig. 1). A rescue was defined as;

At least one individual would be severely injured or killed if the fire department would have arrived 30 min later at the scene.

The time frame of $30 \mathrm{~min}$ was added after a pilot study since the interviewees had difficulties relating to the case of no fire department intervention. It was judged that if the victim was expected to prevail without serious harm for $30 \mathrm{~min}$,

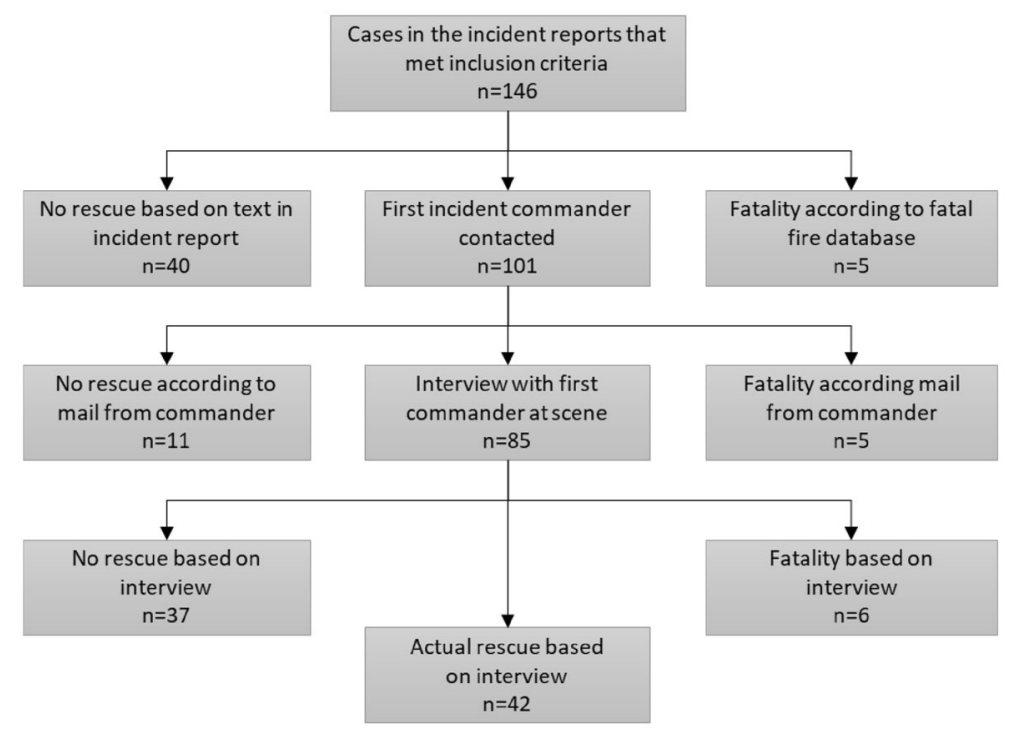

Figure 1. Illustration of inclusion and exclusion of cases based on free text in the incident report (first step), mail contact (second step) and inferview (third step). 
the threat to the individual was limited. It is also difficult to perceive a situation in Sweden where the fire department regularly take more than $30 \mathrm{~min}$ to arrive.

For each case, the interviewee had to prove that there was an imminent threat to the life of the victim. This was performed through description of the fire, location of additional fuel and the condition of the victim at time of rescue. This was normally reinforced with photography and, at one time, video of the fire scene. All cases were also compared with the fatal fires database to verify that the victim had not later died at the hospital.

In total, 42 cases (out of the 146 cases analyzed) qualified as actual rescues. This illustrates that the data in the incident statistics could not be directly used for analyzing cases with rescues since over $70 \%$ of the cases were not true cases according to the definition in this paper. Figure 1 shows a comprehensive view of both included and excluded cases.

Even if 42 cases with, in total, 51 rescued individuals is a significant number compared to the average number of fire related fatalities in residential fires in Sweden (88 fatalities per year in average between 2009 and 2015 [12]), it is a rather small number for statistical analysis. Given the time required to conduct the phone interviews ( 85 were conducted in total, each approximately $30 \mathrm{~min}$ in length) it was not possible to increase this number much further. It is judged that a smaller data set of good quality was more appropriate than a bigger data set of poor quality (which might have been obtained by sourcing e.g. incident statistics). The uncertainty introduced by the limited data set is also consistently analyzed using confidence intervals and significant tests.

In four of the 42 cases, the time of call to the dispatcher was unknown and only the time of first alarm was known. For these cases, the time from call to first alarm was assumed to be equal to the average of the other cases which was 1:31 min (the range among the cases were from $0: 38$ to $4: 45$ ).

Data on fatal fires and fire fatalities are more directly available through the fatal fires database maintained by Swedish Civil Contingencies Agency (MSB), so no interviews were performed for these cases. A close cooperation between MSB and the National Board of Forensic Medicine (RMV) ensures that very few (if any) cases are lacking from the material. The data in the database is gathered from the local fire department and police. The work process ensures high quality data and has been in place since 2009. Therefore this year is chosen to be the first year included in the analysis. Due to problems relating to the new legislation on personal information in Europe known as Global Data Protection Regulation (GDPR) [13], no comparison has been possible between MSB and RMV data for the years 2016 and 2017 and therefore several cases are both lacking and are being included despite not being an actual fire fatality (i.e. the fatality occurred before the fire) [14]. Because of this, only cases up until year 2015 is included. It is unlikely that the nature of these fatalities have changed significantly during the last years and therefore data on fatalities between 2009 and 2015 are compared with rescued individuals during 2017 in this paper. The comparison was performed for persistent variables such as building type and presence of smoke alarm 
as well as scenario specific variables such as cause, object of first ignition and extent of fire (see Appendix).

It was intended to compare the rescues with fatalities in all building fires, however, during 2017 only rescues from residential fires was performed by the fire service. Therefore, the comparison was restricted to residential fires also for fatal fires to support the development of more relevant conclusions.

\subsection{Statistical Methods}

The characteristics of a rescue were analyzed by a comparison with fatal fires on a large number of different variables (see Appendix). The comparison was based on the odds ratio per variable. An odds ratio is the ratio of the odds of an event occurring in one group to the odds of it occurring in another group. It was calculated according to the equation below for an example were the group is people living in apartments.

$$
\left.O R=\frac{\left[\frac{P_{\text {rescue }}}{P_{\text {fatality }}}\right]_{\text {Apartment }}}{\left[\frac{P_{\text {rescue }}}{P_{\text {fatality }}}\right]}\right]_{\text {Notapartment }}
$$

An odds ratio above one indicates that a rescue is more likely in the group in the nominator than in the denominator. The statistical significance of the difference is calculated using a $t$ test for two independent samples. Since the sampling distribution for odds ratios is always positively skewed, a logarithmic scale transformation is performed to compute the standard normal deviate (i.e. Z-score) [15]. The reason for odds ratios being positively skewed are that they are limited on the negative side, since they are always above zero, but not on the positive side [16].

Since multiple comparisons were performed (33 for scenarios and 14 for victims) the significance tests had to be corrected for multiple comparisons. A common method for this is Bonferroni correction. When the number of tests is high, the correction will inflate the risk of type II-error since the P-value will be very small. Therefore, an alternative test developed by Benjamin and Hochberg [17] was performed where a false discovery rate (FDR) is used as an alternative to Ptest. A FDR of between $10 \%$ and $20 \%$ is suggested for testing [18] and therefore both these values were applied to assess the sensitivity of the results to this value.

Fires are inherently destructive events and therefore the number of unknowns are high on several variables for the fatal fires, but generally lower for rescues as the extent of fire is usually smaller (see Appendix). This makes comparison between fatal fires and fires with rescued individuals difficult since cases with rescued individuals will always score significantly lower on "unknown" and significantly higher on several of the others variables. Therefore, unknown values were excluded on a per-variable basis. This leads to an assumption that the variable was distributed in the same way among the unknown cases as for the known.

To derive the probability of rescue depending on response time, logistic regression was employed. This method has been previously used to investigate a similar question [2] and is the natural choice given that the dependent variable is binary 
and the independent variables are a mix of continuous (response time) and categorical. In the analysis, the response time was modeled as a continuous variable (not as percentiles or other possible options) and the categorical variables was coded into dummy variables.

The data set included a 13 times larger number of non-events (fatalities) compared to events (rescues). This is primarily due to the fact that the data set included seven years of fatality data while only a single year of rescued individuals. Unbalanced data (large difference between 1 and 0 in the dependent variables) are often considered a problem for both the predictor values and significance in logistic regression [19] and therefore oversampling was applied where the rescues were duplicated into seven versions. Oversampling is often seen as the best option to deal with unbalanced data [20]. The choice of seven was based on the fact that the fatalities were collected during seven years while rescues were only for a single year and therefore the regression parameters did not have to be corrected. This resulted in that the data set included 259 rescues and 320 fatalities.

\section{Results and Discussion}

\subsection{Frequency and Characteristics of Rescues in Residential Fires}

The interviews revealed that 51 individuals had been saved from 42 different building fires in Sweden during 2017. Based on official monthly population figures for 2017 [21] this translates into 5.1 person per 1,000,000 population and year. Comparing the numbers to the number of fire fatalities in residential fires on average 2009-2015, it can be concluded that the number of fire fatalities would have increased with $58 \%$ (from 88 to 139 fatalities annually) if the fire department would have arrived $30 \mathrm{~min}$ later to the scenes where individuals were rescued. The influence on survivability of shorter increments in response time is discussed in detail in Sect. 3.2.2.

In Fig. 2, it can be seen that a majority of the calls come from a neighbor and this might be one of the reasons that being saved from an apartment (see Appendix) is more likely since the probability of a neighbor smelling the fire or hearing a smoke alarm can be expected to be higher compared to in a house.

In a quarter of the cases $(n=10)$ the victim alerted the fire department themselves and, out of these, a safety alarm, that is used for disabled persons, was used in three cases.

In Fig. 3, the odds ratio of the variables in appendix which had a significant effect on the odds-ratio, with a FDR of $10 \%$, is presented. The error bars are the $95 \%$ confidence interval. An odds ratio above unity indicates that cases within that group has a higher probability of rescue and vice versa.

From Fig. 3, it can be seen that among persistent factors that increase the likelihood of a rescue are living in an apartment and/or close to the fire department. In addition, children and people living with others seem to have better odds at being rescued. The fire related factors with a similar effect are fires occurring in the cooker or deliberate fires, fires that remain small and that the victim takes refuge to the balcony or another fire compartment. It is, however, worth noting 


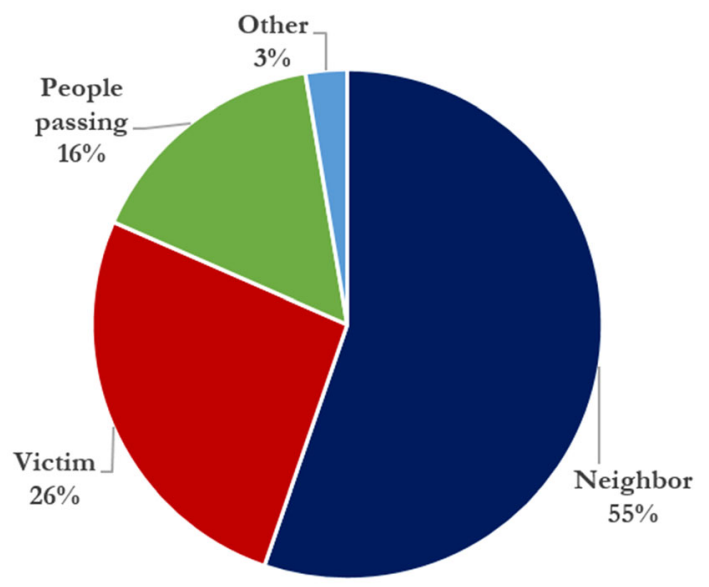

\section{Figure 2. Distribution of the relation between the rescued individual and the individual alerting the fire department.}

that the odds ratio is on a per-variable basis, so it is not corrected for correlations.

\subsection{Needed Capability of Recue Services}

In this section, the capabilities needed by the fire department to perform rescues are analyzed. "Capability" in this context is operationalized to mean the full set of possible tasks that the fire department can use to meet the need together with their respective response time and persistence [22]. Since the rescues in residential fires are generally very short events, persistence is not relevant and therefore the following sections focus on tasks and response time. The impact of the capability on a specific need (in this case being saved from a burning residential structure) is measured as the fraction of cases where the fire service can meet the need (i.e. prevent the fatality).

3.2.1. Actual and Potential Tasks That Could Meet the Need During the analysis, it was found that the victims were rescued either through interior attack or by different types of ladders. Interior attack was either performed with or without a breathing apparatus (BA) depending on the environment in the room. Exterior rescue was used (or could be used) when the victim reached a window or balcony. Depending on the floor where the victim was situated, the rescue could be performed with either a manual ladder and/or an aerial apparatus.

In Fig. 4, it can be seen that interior attack with breathing apparatus (BA) is by far the most common task chosen to perform the rescue in the analyzed cases $(71 \%)$. The remaining three identified tasks make up approximately $10 \%$ each. This could be due to the fact that this is the focus of the training at the fire department and that firefighters typically arrive at the scene dressed with a breathing apparatus; but, in Fig. 5 it can be seen that this is the only task that can meet 


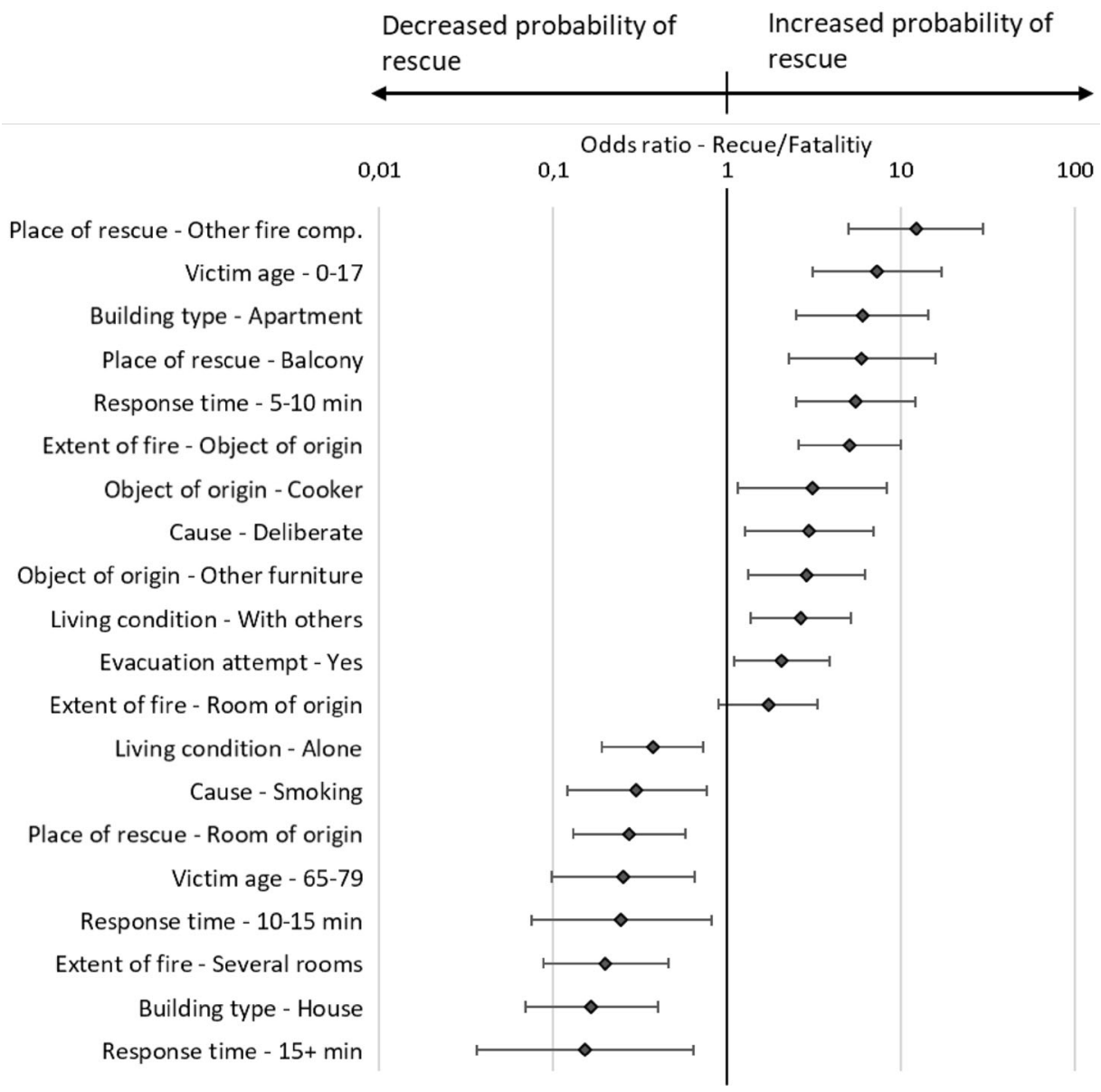

\section{Figure 3. Odds ratios comparing fire and victim characteristics between rescues and fatal fires. Only significant results with a FDR below $10 \%$ is included, for other characteristics, refer to appendix.}

the need (i.e. prevent the fatality) in $40 \%$ of the cases and it can meet the need in $98 \%$ of the cases (all but one case). The distribution of tasks chosen is in line with the findings in the Netherlands [1] for cases of acute threat to life, where interior attack was chosen in $75 \%$ of the cases, aerial apparatus in $19 \%$ of the cases and a manual ladder in $5 \%$ of the cases. However, depending on the standard operating procedures, this might differ between countries.

The fraction of cases where a certain task can meet the need will be labeled the effectiveness of the task in relation to a specified need - in this case the need to be rescued from a burning residential structure. The influence on fire size and location is discussed later in this section.

As can be seen in Fig. 5, an exterior rescue has a potential effectiveness of $28 \%$, but for units that can also perform interior attack with breathing apparatus (BA) 


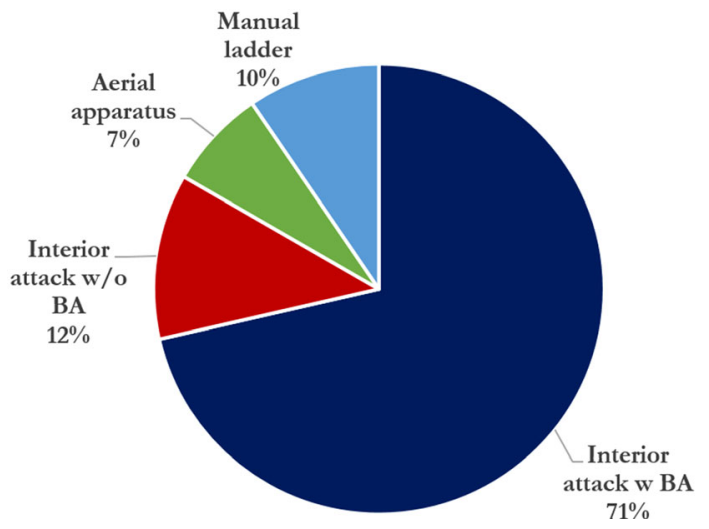

Figure 4. Task performed by the fire service to rescue the individual(s) in the 42 different cases.

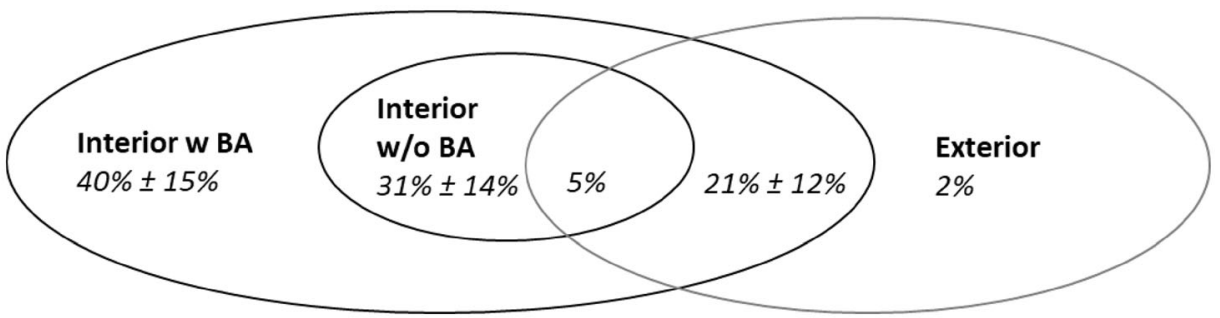

\section{Figure 5. Venn-diagram of tasks that could have been used by the fire service in the 42 different cases. Values fitted with $95 \%$ confidence interval where possible.}

the exterior rescue was only needed in $2 \%$ of the cases (if not chosen above interior attack). This relates to a single case in the database where the presence of acetylene cylinders prevented interior attack, but the victim reached the balcony.

If only interior attack without breathing apparatus is available, the exterior rescues can increase the fraction of rescues that can be performed from $36 \%$ to $59 \%$. The values in Fig. 5 is fitted with a $95 \%$ confidence interval where possible (i.e. both $\mathrm{np}>5$ and $\mathrm{nq}>5$ [23]).

This depends, however, on whether the ladder can reach the affected floor. Especially for the case of manual ladders, this is not generally true and therefore the measure of effectiveness needs to account for the floor level that the ladder can reach. The fraction of apartments in each floor level can be calculated in several different ways. One possibility is to use the floor level where fatal fires have occurred. This accounts for there potentially being a correlation between floor level and risk of fatal fires due to, for example, a joint dependence on socio-economical variables. The negative side of this measurement is that it is not available on the local level (due to too few events) and especially not if a GIS integration of the capability measure is sought (see Sect. 3.2.3). For the local scale and GIS inte- 
gration, statistics on distribution of the number of floor levels in the current building stock can be used. A third option is to use the floor level of the fire from incident statistics that might be a rather stable measure on the municipal level (and easily available for the fire service). In this paper, a national measure is sought and since national statistics on the number of floor levels in the building stock are lacking, the other two options (fatal fires and incidents) are pursued. Data for both fatal fires and incidents are for 2009-2015. Since the difference between the two options was always within $1.5 \%$ of each other on every floor and the average absolute difference was $0.6 \%$, only the results from incidents statistics are presented in this paper.

Assuming that there is no floor level dependence on the overlap between different tasks in Fig. 5, and that all ladders can reach the victim in single-family homes, the fraction of rescues that can be performed with a ladder is found in Fig. 6.

In Fig. 6, it can be seen that if only exterior rescue is available, a ladder that can reach the fourth floor can perform $25 \%$ of the rescues (or $85.2 \%$ of all external rescues) and a ladder that can reach the eighth floor can perform $28 \%$ of the rescues (or $98.6 \%$ of all external rescues). This is assuming that the building is compliant with the building code for fire truck accessibility.

The fraction added when combined with another task, A, can be calculated according to Eq. (2).

$$
\Delta p_{\text {rescue }}=p_{\text {exterior }} \cdot\left(1-p_{\text {taskA }}\right)
$$

All data in this section depends on whether the unit reaches the scene in time to perform the rescue; the probability of this is investigated in the following section. It would be reasonable to think that tasks differ on how sensitive they are to response time since the fires normally has to be smaller for an interior attack without a BA compared to one with a BA. There is, however, no evidence in the

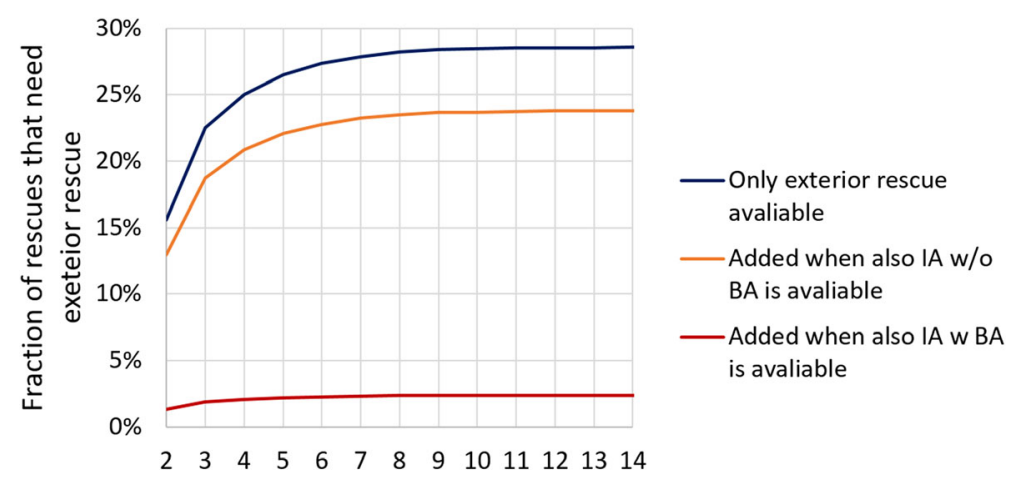

Maximum story possible to perform rescue

Figure 6. Fraction of rescues that need exterior rescue dependent on length of ladder and availability of interior attack (IA) with or without breathing apparatus (BA). 
data that this would be the case since all four tasks have a median response time between $6: 26 \mathrm{~min}$ to $7: 32$. One reason for this might be that the heat release rate of the fire needs to be limited to a certain threshold due to fuel or oxygen limitation to allow a rescue to take place. If the fire grows unrestricted, it is likely that it will cause a fatality much sooner than the time needed for detection (usually by neighbor), alarm and response. The level of this threshold might be more important than the response time to determine the set of possible tasks to perform the rescue. This should however be further investigated in the future.

3.2.2. Response Time In the majority of the cases investigated, it was apparent that a slight increase in response time would have led to a fatality. It is perhaps most evident in two cases where a cigarette induced fire had just transitioned to flaming when the fire department arrived; but even in the other cases it was apparent from the situation and injuries of the individual, that time was of vital importance. Therefore this section focus on an attempt to quantify this importance.

In Fig. 7, it can be seen that the response time for cases with fatalities are generally longer with a median of 9.9 min compared to $7.1 \mathrm{~min}$ for rescues. This can be seen as proof of the importance of response time, but, as is seen in appendix, fatal fires differs significantly from cases with rescues, on a number of variables. In order to quantify the effect of response time and account for these factors, logistic regression was performed. Logistic regression is the natural choice given that the dependent variable (rescue/fatality) is binary. It is also the primary method used by Jaldell et al. [2] when investigating a similar research question, but comparing fatal fires to all fires instead of comparing rescues to fatal fires as is the focus in this paper.

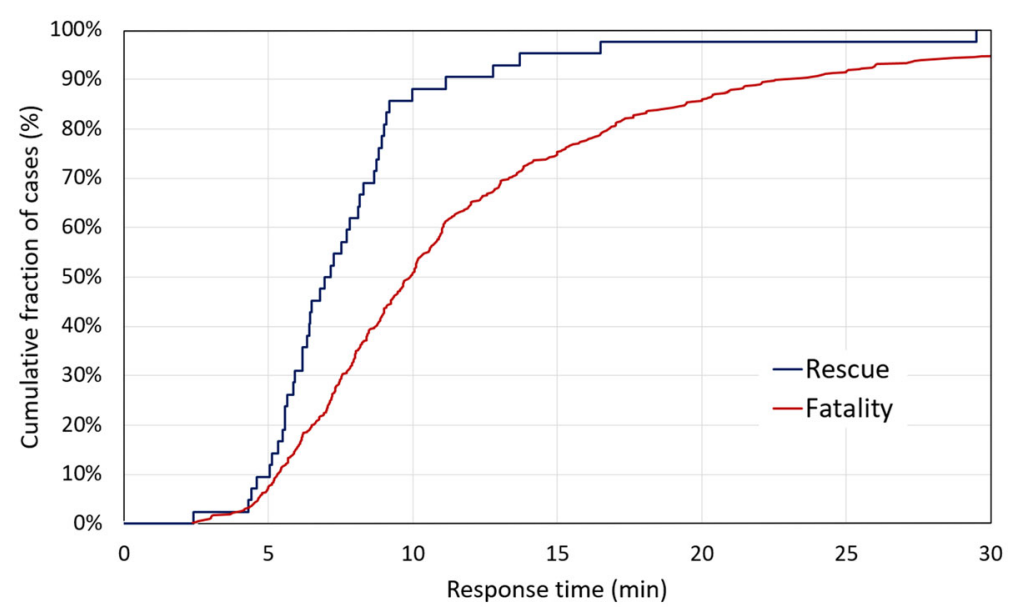

Figure 7. Cumulative distribution of response times for fatal fires ( $N=527$ ) and recues ( $N=42)$. 
Three different models were applied. The first is the naïve model where any difference between the rescue and fatal scenarios was disregarded, the second model accounts for variables in appendix that had a FDR $<10 \%$, and the third accounts for all variables that had a FDR $<20 \%$. No models with all variables was attempted since the ratio of cases to the number of variables must be kept reasonably large [24]. For variables that are perfectly correlated (e.g. Apartment and House), only one variable is included in the model. Further, the two factors relating to number of victims was excluded, so as not to include consequence based parameters. The probability of a successful rescue can be calculated using Eq. (3).

$$
\hat{p}=\frac{e^{\hat{y}}}{1+e^{\hat{y}}}
$$

where $\hat{y}$ is estimated according to below for the different models

$$
\begin{array}{ll}
\hat{y}=\alpha+\beta_{1} \cdot t_{\text {response }} & \\
\hat{y}=\alpha+\beta_{1} \cdot t_{\text {response }}+\sum_{\forall i \in(F D R<0.10)} \beta_{i} \cdot X_{i} & \text { (Model 1) } \\
\hat{y}=\alpha+\beta_{1} \cdot t_{\text {response }}+\sum_{\forall i \in(F D R<0.20)} \beta_{i} \cdot X_{i} & (\text { Model 2) }
\end{array}
$$

Since the number of both rescues and fatalities decreases rapidly outside the range of 5 to $20 \mathrm{~min}$ in response time, only these data points were used in the estima-

\section{Table 1 \\ Coefficients from the Logistical Regression with Rescued Compared to Fatal Fires as Dependent Variables}

\begin{tabular}{llcc}
\hline & Model 1 & Model 2 & Model 3 \\
\hline Intercept, $\alpha$ & $1.633^{* * *}$ & 1.089 & 1.302 \\
Time effect, $\beta_{1}$ & $-0.210^{* * *}$ & $-0.139^{* * *}$ & $-0.150^{* * *}$ \\
Apartment effect, $\beta_{2}$ & - & $0.791^{* * *}$ & $0.739^{*}$ \\
InStartobject effect, $\beta_{3}$ & - & $1.555^{* * *}$ & $1.387^{* *}$ \\
InSeveralRooms effect, $\beta_{4}$ & - & $-0.582^{*}$ & -0.713 \\
Other furniture effect, $\beta_{5}$ & - & $1.267^{* *}$ & $1.454^{* * *}$ \\
Smoking effect, $\beta_{6}$ & - & $-2.318^{* * *}$ & $-2.539^{* * *}$ \\
Deliberate effect, $\beta_{7}$ & - & 2.245 & 2.012 \\
Cooker effect, $\beta_{8}$ & - & $0.740^{*}$ & $0.838^{*}$ \\
Upholstered furniture effect, $\beta_{9}$ & - & - & $0.650^{* *}$ \\
InStartroom effect $\beta_{10}$ & - & - & -0.196 \\
Cox and Snell R & 0.089 & 0.311 & 0.317 \\
Nagelkerke R & & 0.425 & 0.432 \\
\hline
\end{tabular}

Three different sets of independent variables presented with only response time (Model 1) or also all univariately significant independent variables with FDR $<0.10$ (Model 2) or FDR $<0.20$ (Model 3)

$* * * P<0.01 ; * * P<0.05 ; * P<0.10)$ 
tion. This covers $88 \%$ of the rescues and $63 \%$ of the fatal fires and it also covers the situation in most areas in Sweden.

The result of the logistic regressions is shown in Table 1.

From Table 1, it can be found that the time effect is highly significant $(P<0.01)$ for all three models. It is also clear that smoking related scenarios $\left(\beta_{6}\right)$ had a lower probability of rescue, while smaller fires $\left(\beta_{3}\right.$ and $\left.\beta_{4}\right)$ and fires in apartments $\left(\beta_{2}\right)$ had a higher probability. The effect of a fire being deliberate $\left(\beta_{7}\right)$ becomes non-significant when response time and other scenario factors are taken into account.

In Fig. 8, the empirical distribution of probability of rescue can be found together with the logistic regression according to model 1 to 3. Models 2 and 3, which account for the difference between fatal fires and rescues, yield a lower dependence of response time but still highly significant $(P<0.01)$. Note that models 2 and 3 are multidimensional and the curve in Fig. 8 is only representative for average values of the independent variables.

It is not obvious which model is better to assess the capability of the fire service. There is a correlation between type of scenario and response time in practice and since the capability assessment is most likely to be performed to compare different options, the slope of the curve is judged to be more important than the absolute value. Models 2 and 3 give similar pseudo- $\mathrm{R}^{2}$-values and therefore either of them can be used, but model 3 was chosen for the analysis in this paper.

Due to the limited data set, quantification of the uncertainty in the dependent variable is needed. This was performed using the bootstrap method with 30,000

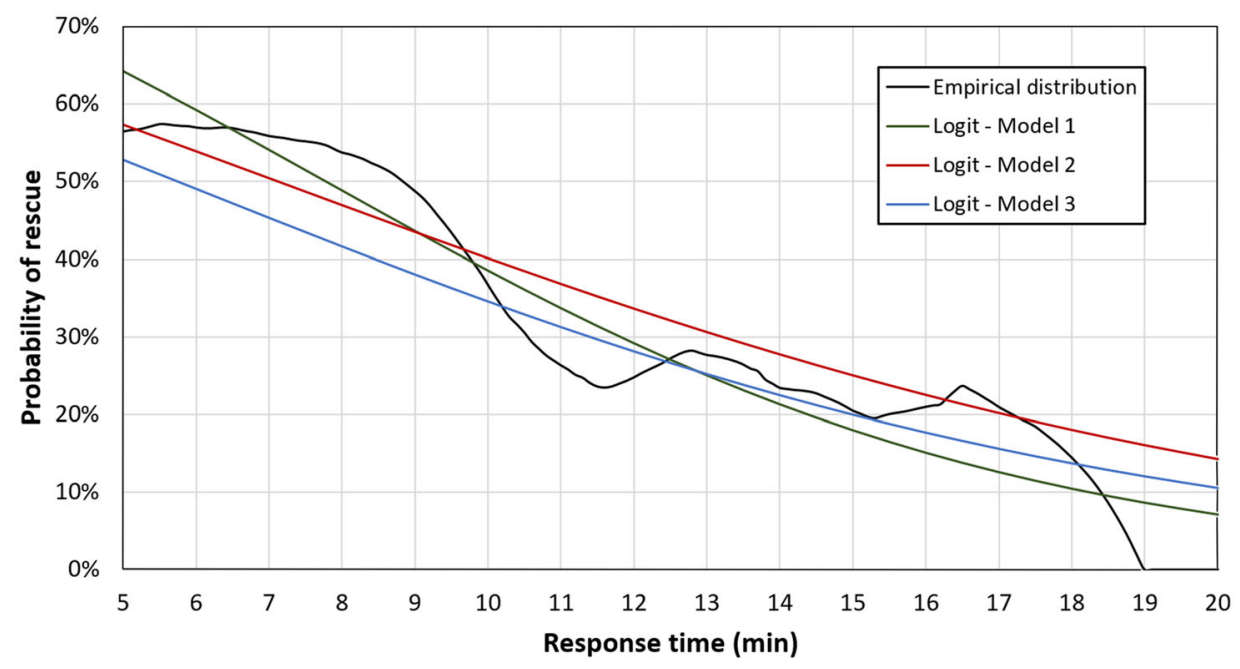

Figure 8. Probability of rescue for different response times. Empirical distribution is based on a 5 min moving average with triangular weighting and compared to logistic regression according to the three models. 
samples [25]. The empirical distribution of the dependent variable in the regression is found in the Fig. 9.

The uncertainty is also presented as a confidence interval in Fig. 10. Since the data is not normally distributed and, at least for shorter response times, shows a distinct bimodular structure. The upper tail will give a very large confidence interval. However, reducing the level of certainty slightly from the generally used $97.5 \%$ to $82.5 \%$ or $92.5 \%$ was found to have a very large effect on the upper confidence bound.

The result in Fig. 10 show that the lower confidence bound for a $95 \%$ confidence interval is reasonably close to the predicted value (between 8 and $11 \%$ below the predicted) while the upper bound is very broad with $25 \%$ to $33 \%$ over prediction. This is due to the long upper tail previously discussed. However, a decrease in the level of confidence to $80 \%$ will reduce this upper bound to between $6 \%$ and $11 \%$ above the predicted value. Therefore, the actual probability of recue will, with $80 \%$ probability of rescue, be within $6 \%$ and $11 \%$ from the predicted value depending on the response time.

Based in this regression, the probability of rescue, if the same types of scenarios would occur independent of the response time, and can be calculated according to Eq. (4).

$$
p_{\text {rescue }}=\frac{e^{0.864-0.150 t}}{1+e^{0.864-0.150 t}}
$$

Using this result, together with the method to calculate the marginal effect in Jaldell et al. [2], it was found that a reduction in mean response time in the range 5

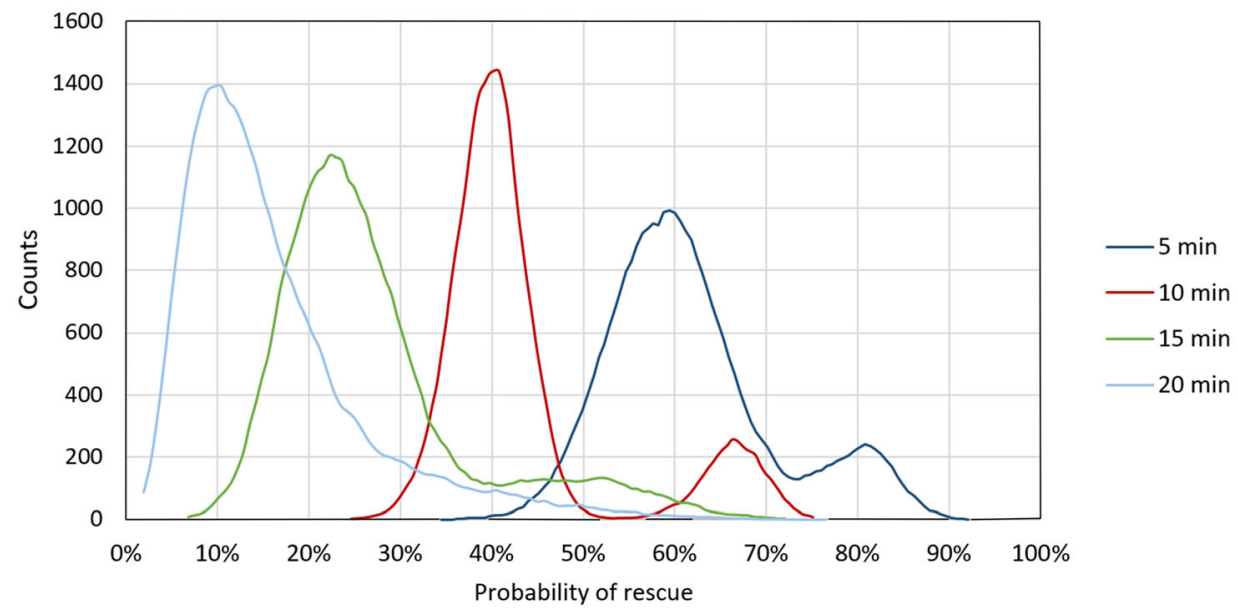

Figure 9. Empirical distributions of the probability of rescue according to model 3 at certain response times. The distributions are based on bootstrap with 30,000 samples with curves fitted to a 100 bin histogram with a three bin moving average. 


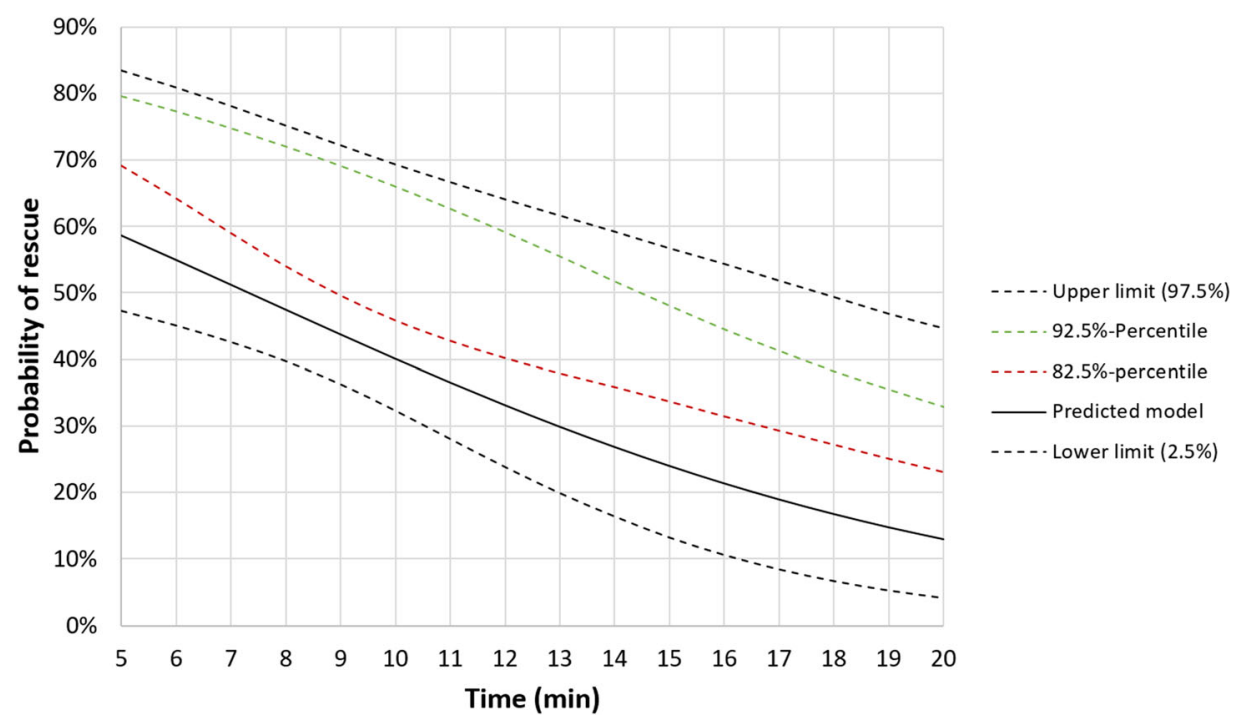

\section{Figure 10. Probability of rescue for model 3 with $95 \%$ confidence inferval and $\mathbf{8 2 . 5 \%}$ - and $\mathbf{9 2 . 5 \%}$-percentiles.}

to $20 \mathrm{~min}$ (which is $9 \mathrm{~min}$ ) by $1 \mathrm{~min}$ would save 5 lives annually, to be compared with the previous result of 2 lives annually. One possible explanation for this difference might be that Jaldell et al. [2] included all cases with response time between 0 and $30 \mathrm{~min}$, while the current paper restricted the range to between 5 and 20 min. It is not unlikely that the dependence on time is different in this smaller range.

Equation (4) is based on the current effectiveness of the different units arriving at the scene; but, to be able to compare different types of units, a theoretical upper limit for the probability of a successful rescue given an effectiveness of the first unit arriving of $100 \%$ needs to be calculated. The type of unit arriving is not available for the entire time series since it was not collected in the incident statistics until 2016. Even during year 2016 and 2017 there is not a full coverage of the new reporting sheet and for year 2017, not all reports have been submitted. For the 207 fatal fires currently in the database, the new reporting sheet is available for 110 cases $(53 \%)$ ). For these, a small unit with 1-2 firefighters, that could only perform interior rescue without BA and not ladder rescue, was first at scene at $12.7 \%$ of the fatal fires. For the remaining cases it is a larger unit (typically an engine) and, even if another unit arrived first at the scene, the engine is typically seconds after since they tend to travel together. There might be a few cases where the command vehicle (that arrived first in $16 \%$ of the cases) was at a different location from the crew and arrived sooner to the scene, but this is not possible to assess and likely to be within the margin of error in this paper.

The effectiveness of the large unit (that can perform interior attack with BA and ladder rescue) is between $99.6 \%$ (if they do not have an aerial apparatus) and $100 \%$ (if they do). This difference is negligible and therefore $100 \%$ is used in the 
correction. The effectiveness of the small unit is $36 \%$ since they can only perform interior rescue without a breathing apparatus and no exterior rescue. Therefore, the correction of Eq. (4) for the hypothetical case of $100 \%$ effectiveness in all cases can be calculated according since a small unit arrived significantly sooner in $12.7 \%$ of the cases.

$$
\begin{aligned}
& p_{\text {rescue }, 100 \%}=\frac{1}{0.127 \cdot 0.36+0.873 \cdot 1.0} \cdot \frac{e^{0.864-0.150 t}}{1+e^{0.864-0.150 t}} \\
& p_{\text {rescue }, 100 \%}=1.089 \cdot \frac{e^{0.864-0.150 t}}{1+e^{0.864-0.150 t}}
\end{aligned}
$$

3.2.3. Combining Tasks and Response Time to Measure Capability In Sect. 3.2.1 it was found that there was no apparent correlation between the set of tasks that could be used and response time. The dataset is, however, too small to decisively prove that this is the case and therefore this should be investigated further in the future. If we, assume that this is the case, we can apply the conclusions in Sects. 3.2.1 and 3.2.2 independently to assess the capability. Therefore, the probability of successfully performing a rescue for a certain unit can be calculated according to below.

$$
p_{\text {rescue }, \text { UnitA }}=E_{\text {UnitA }} \frac{1.089 e^{0.864-0.150 t}}{1+e^{0.864-0.150 t}}
$$

The time variable above can be a fixed value, but also, which is more relevant in practice, a random variable. In the case of time being a random variable the probability can be estimated using the bootstrap methodology [25]. It could also be of value to implement the equation into a GIS-environment to assess the capability both in the normal situation and dynamically during an event.

3.2.4. On the Reliability and Validity of the Numbers Presented The analysis in the current paper is based on a rather limited number of cases. Therefore careful analysis and quantification of uncertainties has been performed. The low number of cases, however, does limit the statistical power of the significance tests. The level of uncertainty can be reduced if a larger dataset is gathered in future studies. The precision achieved, however, is judged to be sufficiently high to make the model useful in practice.

The determination of whether the individuals were at immediate threat of the fire or not is entirely based on the joint judgement of the researcher and fire commander and is, to some extent, subjective. In many cases the threat was obvious due to the scenario and condition of the victim, but there were also a few cases which were more difficult to determine. The procedure was, however, identical across response times, tasks and scenarios so, even if there might be errors in judgement, it is thought to influence primarily the absolute probability of a successful rescue. Since the measure developed in this paper is expected to be used 
mostly for comparison between different situations, geographical regions and options, they are judged to be less sensitive to errors in judgement.

\section{Conclusions}

The results in this study showed that fire departments saved 51 individuals from 42 fires in Sweden during 2017. This is equal to 5.1 lives per 1,000,000 in population. This shows that the annual number of fire fatalities would have increased by $58 \%$ without intervention from the fire departments.

Interior attack with breathing apparatus is the most common task used to perform the rescue $(71 \%)$ and it could have been used to perform $98 \%$ of the rescues. Interior attack without breathing apparatus could be used in $36 \%$ of the cases and exterior rescue in $28 \%$. The last number depends on whether the ladder reaches the affected floor and the probability of this being the case has been derived.

With the current distribution of units, a reduction of the mean response time of 1 min will prevent 5 individuals annually from dying in fires which is higher than previously reported (2 individuals [2]).

The probability of a successful rescue can be calculated using the equation below.

$$
p_{\text {rescue,UnitA }}=E_{\text {UnitA }} \frac{1.089 e^{0.864-0.150 t}}{1+e^{0.864-0.150 t}}
$$

where $t$ is the response time and $E_{\text {Unit }}$ is the joint effectiveness of the tasks that the unit can perform. This value can be found in Figs. 5 and 6. The uncertainty in the quota can be found in Fig. 10.

The joint probability for all available units is a measure of the impact of the capability on the specific need - in this case being saved from a burning building. This measure can be used for both long-term planning, and normative command and control, to retain an adequate capability during other large events. The usefulness of the equation would increase if combined with a measure of expected frequency of fatalities in different locations based on the research on risk factors for fatal fires (e.g. [26]).

While the paper does provide support for planning of the fire service, the results should be put in a wider context before applying them to planning since they only cover a part of the purpose of the fire service.

To reduce the uncertainty in the measures, a larger data set should be pursued. However, the level of confidence in the results is judged to be adequate for practical use as a model to analyze the influence the changes in capability in the fire service. This is the first time there is a model available that take into account both response time and the capability of the unit responding to calculate the probability of a successful rescue in fires. 


\section{Acknowledgements}

Open access funding provided by Lund University. This research was funded by the Swedish Civil Contingencies Agency (MSB). The author would also like to thank all commanders that volunteered for interviews. Special thanks also to Dr. Carl Bonander, Assistant Professor in epidemiological methods at University of Gothenburg, Sweden, for help with the quantification of the uncertainty.

\section{Open Access}

This article is distributed under the terms of the Creative Commons Attribution 4.0 International License (http://creativecommons.org/licenses/by/4.0/), which permits unrestricted use, distribution, and reproduction in any medium, provided you give appropriate credit to the original author(s) and the source, provide a link to the Creative Commons license, and indicate if changes were made.

\section{Appendix: Comparison Between Rescues and Fatal Fires}

See Tables 2 and 3.

Table 2

Comparison of Fire Events with Rescues and Fatalities, with Odds Ratio (OR) for the Odds of Being Rescued

\begin{tabular}{|c|c|c|c|}
\hline & $\begin{array}{l}\text { Rescues } \\
\% \text { (no. fires) } \\
n=42\end{array}$ & $\begin{array}{c}\text { Fatal fires } \\
\% \text { (no. fires) } \\
n=551\end{array}$ & $\begin{array}{l}\text { Odds ratio } \\
\text { Rescue/fatality }\end{array}$ \\
\hline \multicolumn{4}{|l|}{ Building type } \\
\hline Apartment & $86 \%(36)$ & $50 \%(275)$ & $6.022 * *$ \\
\hline House & $14 \%(6)$ & $50 \%(276)$ & $0.166^{* *}$ \\
\hline \multicolumn{4}{|l|}{ Time of day } \\
\hline Day time (06-22) & $69 \%(29)$ & $58 \%(321)$ & 1.598 \\
\hline Night time (22-06) & $31 \%(13)$ & $37 \%(202)$ & 0.774 \\
\hline \multicolumn{4}{|l|}{ Room of origin } \\
\hline Kitchen & $26 \%(11)$ & $19 \%(79)$ & 1.527 \\
\hline Living room & $26 \%(11)$ & $32 \%(135)$ & 0.746 \\
\hline Bedroom & $26 \%(11)$ & $27 \%(113)$ & 0.961 \\
\hline Other & $21 \%(9)$ & $22 \%(92)$ & 0.969 \\
\hline Unknown & 0 & 132 & \\
\hline \multicolumn{4}{|l|}{ Object of origin } \\
\hline Upholstered furniture & $20 \%(7)$ & $29 \%(121)$ & $0.413^{*}$ \\
\hline Other furniture and building contents & $31 \%(11)$ & $11 \%(44)$ & $2.885^{* *}$ \\
\hline Clothing & $9 \%(3)$ & $10 \%(41)$ & 0.640 \\
\hline Cooker & $17 \%(6)$ & $5 \%(20)$ & $3.114^{* *}$ \\
\hline Electrical installation & $9 \%(3)$ & $10 \%(43)$ & 0.606 \\
\hline Flammable liquid or gas & $6 \%(2)$ & $4 \%(15)$ & 1.236 \\
\hline
\end{tabular}


Table 2

continued

\begin{tabular}{|c|c|c|c|}
\hline & $\begin{array}{l}\text { Rescues } \\
\% \text { (no. fires) } \\
n=42\end{array}$ & $\begin{array}{l}\text { Fatal fires } \\
\% \text { (no. fires) } \\
n=551\end{array}$ & $\begin{array}{l}\text { Odds ratio } \\
\text { Rescue/fatality }\end{array}$ \\
\hline Other & $9 \%(3)$ & $9 \%(37)$ & 0.720 \\
\hline Unknown & 7 & 230 & \\
\hline \multicolumn{4}{|l|}{ Cause of fire } \\
\hline Smoking & $20 \%(6)$ & $45 \%(129)$ & $0.302 * *$ \\
\hline Deliberately set & $30 \%(9)$ & $13 \%(36)$ & $2.964 * *$ \\
\hline Cooking appliance left on & $17 \%(5)$ & $7 \%(20)$ & $2.650^{*}$ \\
\hline Technical fault & $10 \%(3)$ & $7 \%(19)$ & 1.556 \\
\hline Other & $30 \%(9)$ & $28 \%(81)$ & 1.079 \\
\hline Unknown & 12 & 266 & \\
\hline \multicolumn{4}{|l|}{ Smoke alarm } \\
\hline Present and functional & $50 \%(10)$ & $41 \%(128)$ & 1.422 \\
\hline Not present or not functional & $50 \%(10)$ & $59 \%(182)$ & 0.703 \\
\hline Unknown & 22 & 241 & \\
\hline \multicolumn{4}{|l|}{ Number of fatalities/rescues } \\
\hline 1 & $88 \%(37)$ & $92 \%(506)$ & $0.336^{*}$ \\
\hline 2 & $5 \%(2)$ & $6 \%(35)$ & 0.706 \\
\hline $3+$ & $7 \%(3)$ & $2 \%(10)$ & $3.992 *$ \\
\hline \multicolumn{4}{|l|}{ Extent of fire on arrival } \\
\hline Not burning & $0 \%(0)$ & $9 \%(49)$ & $\mathrm{N} / \mathrm{A}$ \\
\hline Object of origin & $38 \%(16)$ & $11 \%(57)$ & $5.096^{* *}$ \\
\hline Room of origin & $38 \%(16)$ & $26 \%(139)$ & $1.727^{*}$ \\
\hline Several room (in same fire compartment) & $17 \%(7)$ & $50 \%(264)$ & $0.201 * *$ \\
\hline Several fire compartments & $7 \%(3)$ & $4 \%(20)$ & 1.958 \\
\hline Unknown & 1 & 22 & \\
\hline \multicolumn{4}{|l|}{ Response time } \\
\hline$<5 \min$ & $10 \%(4)$ & $7 \%(37)$ & 1.400 \\
\hline $5-10 \mathrm{~min}$ & $81 \%(34)$ & $44 \%(230)$ & $5.525^{* *}$ \\
\hline $10-15 \min$ & $7 \%(3)$ & $24 \%(126)$ & $0.246^{* *}$ \\
\hline $15+\min$ & $5 \%(2)$ & $25 \%(130)$ & $0.153^{* *}$ \\
\hline Unknown & 0 & 28 & \\
\hline
\end{tabular}

**FDR $<0.10 ; *$ FDR $<0.20$ 


\section{Table 3}

Comparison of Individuals Rescued and Killed in Fires, with Odds Ratio (OR) for the Odds of Being Rescued

\begin{tabular}{|c|c|c|c|}
\hline & $\begin{array}{l}\quad \text { Rescued } \\
\% \text { (no of individu- } \\
\text { als) } \\
n=51\end{array}$ & $\begin{array}{c}\text { Fatalities } \\
\begin{array}{c}\text { \% (no of individu- } \\
\text { als) } \\
n=608\end{array}\end{array}$ & $\begin{array}{c}\text { Odds ratio } \\
\text { Rescue/Fatal- } \\
\text { ity }\end{array}$ \\
\hline \multicolumn{4}{|l|}{ Age group } \\
\hline $0-17$ years & $20 \%(9)$ & $43(20)$ & $7.350^{* * *}$ \\
\hline $18-64$ years & $56 \%(25)$ & $43 \%(260)$ & 1.673 \\
\hline 65-79 years & $11 \%(5)$ & $33 \%(201)$ & $0.253^{* *}$ \\
\hline $80+$ years & $13 \%(6)$ & $21 \%(127)$ & 0.583 \\
\hline Unknown & 5 & & \\
\hline \multicolumn{4}{|l|}{ Gender } \\
\hline Male & $54 \%(27)$ & $61 \%(370)$ & 0.755 \\
\hline Female & $47 \%(18)$ & $39 \%(238)$ & 1.324 \\
\hline Unknown & 1 & 0 & \\
\hline \multicolumn{4}{|l|}{ Living conditions } \\
\hline With others & $53 \%(20)$ & $29 \%(153)$ & $2.680^{* *}$ \\
\hline Alone & $47 \%(18)$ & $71 \%(369)$ & $0.373^{* *}$ \\
\hline Unknown & 13 & 56 & \\
\hline \multicolumn{4}{|l|}{ Place of fatality/rescue } \\
\hline In room of origin & $18 \%(9)$ & $44 \%(221)$ & $0.272^{* *}$ \\
\hline $\begin{array}{l}\text { In other room in same fire compart- } \\
\text { ment }\end{array}$ & $47 \%(24)$ & $51 \%(257)$ & 0.847 \\
\hline In other fire compartment & $22 \%(11)$ & $2 \%(11)$ & $12.275^{* *}$ \\
\hline Balcony/outside & $14 \%(7)$ & $3 \%(13)$ & $5.984 * *$ \\
\hline Unknown & 0 & 64 & \\
\hline \multicolumn{4}{|l|}{ Attempted evacuation } \\
\hline Yes & $65 \%(32)$ & $48 \%(136)$ & $2.076^{* *}$ \\
\hline No & $35 \%(17)$ & $52 \%(150)$ & $0.482^{* *}$ \\
\hline Unknown & 2 & 332 & \\
\hline
\end{tabular}

$* *$ FDR $<0.10 ; *$ FDR $<0.20$

\section{References}

1. Kobes M, Van Den Dikkenberg R (2016) An analysis of residential building fire rescues: the difference between fatal and nonfatal casualties. In: Interflam 2016: 14th international fire science and engineering conference. Interscience, pp 353-364

2. Jaldell H (2016) How important is the time factor? Saving lives using fire and rescue services. Fire Technol 53:1-14. https://doi.org/10.1007/s10694-016-0592-4

3. Ulander A (2015) Optimization based decision support tools for fire and rescue resource planning. Licentiate Thesis, Linköping Universit, Sweden

4. Hogg JM (1968) The siting of fire stations. J Oper Res Soc 19:275-287. https://doi.org/ 10.1057 jors. 1968.71

5. Andersson T, Särdqvist S (2007) Planning for effective use of fire and rescue service resources. In: Interflam 2007 11th international fire science and engineering conference, pp 1561-1566 
6. Jaldell H (2019) Measuring productive performance using binary and ordinal output variables: the case of the Swedish fire and rescue services. Int J Prod Res 57:907-917. https://doi.org/10.1080/00207543.2018.1489159

7. Challands N, Zealand N, Service F (2014) The relationships between fire service response time and fire outcomes. https://doi.org/10.1007/s10694-009-0111-y

8. Ignall E, Rider KL, Urbach R (1978) Fire severity and response distance: initial findings. R-2013-NYC, The New York City-Rand Institute

9. Mattsson B, Juås B (1997) The importance of the time factor in fire and rescue service operations in Sweden. Accid Anal Prev 29:849-857

10. Mcintyre C (2014) Insatsstatistik 2013-Beskrivning av statistiken ["Incident statistics-Description of the statistics"; in Swedish]. Karlstad: Swedish Civil Contingencies Agency (MSB)

11. Sund B, Moln Teike J (2015) Lägesbild [“Current situation”; In Swedish]. In: Räddningstjänstanalys 2015 [“Analysis of the rescue services 2015”]. Karlstad: Swedish Civil Contingencies Agency (MSB)

12. MSB (2018) Indicators, data \& analysis (IDA). http://ida.msb.se. Accessed 31 Oct 2018

13. EU (2016) General Data Protection Regulation (GDPR). Regulation of the European Parliament and of the Council

14. Jonsson A, Bergqvist A, Andersson R (2015) Assessing the number of fire fatalities in a defined population. J Saf Res 55:99-103. https://doi.org/10.1016/j.jsr.2015.10.001

15. Sheskin DJ (2004) Handbook of parametric and nonparametric statistical procedures, 3rd edn. Chapman \& Hall/CRC, Boca Raton, p. 542

16. Bland JM, Altman DG (2000) The odds ratio. BMJ 320:1468

17. Benjamini Y, Hochberg Y (1995) Controlling the false discovery rate: a practical and powerful approach to multiple testing. J R Stat Soc B57:289-300

18. McDonald JH (2014) Handbook of biological statistics, 3rd edn. Sparky House Pubishing, Baltimore, pp. 245-260

19. Salas-Eljatib C, Fuentes-Ramirez A, Gregoire TG, Altamirano A, Yaitul V (2018) A study on the effects of unbalanced data when fitting logistic regression models in ecology. Ecol Indic 85:502-508. https://doi.org/10.1016/j.ecolind.2017.10.030

20. Crone SF, Finlay S (2012) Instance sampling in credit scoring: an empirical study of sample size and balancing. Int J Forecast 28:224-238. https://doi.org/10.1016/j.ijforecast.2011.07.006

21. SCB (2018) Population statistics. http://www.scb.se/be0101. Accessed 26 Jun 2018

22. Runefors M (2017) An operationalization of capabilities for fire and rescue operations. In: Nordic fire \& safety days, Aug 17-18 2017. RISE, Copenhagen, Denmark, p 55

23. Fleming M, Nellis J (2000) Principles of applied statistics, 2nd edn. Thomson Learning, Boston

24. Tabachnic B, Fidell L (2007) Using multivariate statistics, 5th edn. Pearson, Boston, p. 442

25. Efron B (1979) Bootstrap methods: another look at the jackknife. Ann Stat 7:1-26. https://doi.org/10.1214/aos/1176344552

26. Jonsson A, Bonander C, Nilson F, Huss F (2017) The state of the residential fire fatality problem in Sweden: epidemiology, risk factors, and event typologies. J Saf Res 62:89-100

Publisher's Note Springer Nature remains neutral with regard to jurisdictional claims in published maps and institutional affiliations. 